\title{
JURISPRUDENCIA CONSTITUCIONAL EN MATERIA DE PROTECCIÓN DEL MEDIO AMBIENTE
}

\author{
JORDI JARIA I MANZANO \\ Profesor agregado interino de Derecho Constitucional \\ Universitat Rovira i Virgili
}


Sumario: 1. Miscelánea competencial. 1.1. Problemas competenciales ambientales en una ley de acompañamiento. 1.2. Otro caso de multiplicidad competencial: la Ley de Economía Sostenible. 2. Subvenciones en relación con asociaciones y fundaciones relacionadas con la protección del medio ambiente. 3. Caza y protección del medio ambiente: la proyección de la legislación básica como protección mínima sobre la normativa autonómica en el ámbito de la caza. 4. La protección de la biodiversidad: materia controvertida. 4.1. Nuevamente, la Ley 42/2007 a discusión. 4.2. Determinación de las especies protegidas

\section{Miscelánea competencial}

\subsection{Problemas competenciales ambientales en una ley de acompañamiento}

La utilización sistemática de las llamadas leyes de acompañamiento de los presupuestos es, como se sabe, una cuestión ciertamente polémica que da lugar a una significativa conflictividad ante el Tribunal Constitucional, en la mayoría de ocasiones por cuestiones competenciales. Comenzamos esta crónica con una sentencia que no entró en la anterior por cuestión de días y donde se resuelven diferentes cuestiones, algunas de ellas relativas a temas ambientales — dado, justamente, el carácter heterogéneo de la ley impugnada, los frentes abiertos son múltiples, de modo que solo procede un comentario parcial de la resolución, en relación con aquellas cuestiones vinculadas a la conflictividad competencial en materia ambiental—. Me refiero a la Sentencia 104/2013, de 25 de abril de 2013 (BOE, núm. 123, de 23 de mayo de 2013), que resuelve un recurso de inconstitucionalidad interpuesto por el Gobierno catalán contra la Ley 62/2003, de 30 de diciembre, de medidas fiscales, administrativas y del orden social, esto es, la ley de acompañamiento de los presupuestos para el ejercicio 2004. Por cierto, debe notarse que, en la posterior Sentencia 111/2013, de 9 de mayo de 2013 (BOE, núm. 133, de 4 de junio de 2013), el Tribunal se remite a lo resuelto aquí y a lo que ya desarrolló en las SSTC 149/2012, de 5 de julio, 36/2013, de 14 de febrero, y 59/2013, de 13 de marzo, ya comentadas en crónicas anteriores, por lo que me voy a abstener de comentarla en esta ocasión.

La Sentencia comentada se refiere a diferentes cuestiones, a saber: el artículo 33.2 a), relativo a una de las funciones que se atribuyen al Consejo para la promoción de la igualdad de trato y no discriminación de las personas por el origen racial o étnico; el artículo 46, que introduce diferentes modificaciones en el texto refundido de la Ley sobre infracciones y sanciones en el orden social, aprobado por el Real Decreto Legislativo 5/2000, de 4 de agosto; el artículo 120, según el cual el régimen de pago único de las ayudas directas en materia agrícola previstas en el Reglamento (CE) núm. 
1782/2003 del Consejo, de 29 de septiembre, se aplicará en todo el territorio nacional; el artículo 127.3, relativo a la declaración de impacto ambiental; los artículos 122 (aguas), 128.2 (residuos) y 129.7 y 21 (aguas, de nuevo), referidos a diferentes cuestiones de carácter ambiental a criterio del recurrente; la disposición adicional vigesimotercera, por la que se deroga el apartado 1 a) de la disposición adicional décima de la Ley 10/2001, de 5 de julio, del Plan Hidrológico Nacional, precepto que preveía la elaboración del Plan Integral de Protección del Delta del Ebro; y, finalmente, la disposición adicional trigésima, que establece unas obligaciones de programación y unos límites en relación con la posibilidad de emitir en cadena aplicables a los titulares de concesiones de ámbito estatal o autonómico de servicios de televisión digital terrestre y de televisión local por ondas terrestres.

Dejando aparte las cuestiones no ambientales de la Sentencia, cabe tener en cuenta que el Tribunal Constitucional se pronuncia en relación con el artículo 127 de la Ley 62/2003 de acuerdo con lo ya establecido en las SSTC 149/2012, de 5 de julio, y STC 59/2013, de 13 de marzo, ya citadas anteriormente y comentadas en las dos crónicas anteriores - la primera de ellas, coincidente en el objeto con la que aquí nos ocupa-; de hecho, lo volverá hacer, en el mismo sentido, en la Sentencia 180/2013, de 23 de octubre de 2013 (BOE, núm. 278, de 20 de noviembre de 2013), que reitera los argumentos de las dos resoluciones citadas. Ya me he expresado críticamente, en las crónicas mencionadas, en relación con la doctrina del Tribunal Constitucional en esta materia, de modo que no voy a insistir aquí en ello. Por otro lado, el impugnado artículo 129 también fue enjuiciado en la citada STC 149/2012, de 5 de julio, tomando como referencia la STC 227/1988, de 29 de noviembre, que se pronunció en su momento sobre la Ley de Aguas. El pronunciamiento del Tribunal se reiteraría, posteriormente, en la citada STC 180/2013, de 23 de octubre. Me remito, de nuevo, al comentario a la primera de las sentencias citadas, que realicé en la crónica correspondiente al núm. 3-2 de la revista.

Por otro lado, lo que ofrecía mayor interés desde el punto de vista de la protección constitucional del medio ambiente y el alcance del artículo $45 \mathrm{CE}$ como parámetro en el control de constitucionalidad, esto es, la impugnación de la disposición adicional vigesimotercera, el TC considera que ha quedado sin objeto a partir de la aprobación de la Ley 11/2005, de 22 de junio, con lo que, una vez más, el juez de constitucionalidad logra soslayar la cuestión. Dicho esto, en esta crónica me voy a centrar en lo establecido 
por el Tribunal Constitucional en relación con los artículos 122 y 128 de la Ley $62 / 2003$

En cuanto al artículo 122 de la Ley 62/2003, este añadía un nuevo párrafo al apartado 2 del artículo 127 del texto refundido de la Ley de Aguas, aprobado por Real Decreto Legislativo 1/2001, de 20 de julio, con la siguiente redacción: “El informe previo será emitido, a petición del Ministerio de Medio Ambiente o sus organismos autónomos, por las entidades locales afectadas por las obras. El informe deberá pronunciarse exclusivamente sobre aspectos relacionados con el planeamiento urbanístico y se entenderá favorable si no se emite y notifica en el plazo de un mes". La representación procesal del Gobierno catalán consideraba que tal previsión resultaría "excluyente del resto de competencias municipales y contrario al principio de autonomía local de los arts. 137 y 140 CE", y, por ende, inconstitucional. A partir de la consideración de que "la autonomía local es un concepto jurídico de contenido legal, que permite, por tanto, configuraciones legales diversas, válidas en cuanto respeten aquella garantía institucional", asentada en su propia doctrina (STC 170/1989, de 19 de octubre, FJ 9. ${ }^{\circ}$ ), y de que el precepto se incardina sistemáticamente en la intervención municipal en relación con los aspectos urbanísticos que la obra pueda suscitar, el Tribunal Constitucional resuelve salvando la constitucionalidad de la disposición impugnada.

En cuanto al 128.2, que modifica el párrafo segundo del apartado 4 del artículo 27 de la Ley 10/1998, de 21 de abril, de Residuos, en el sentido de que la remisión de los informes de situación que deben presentar los titulares de actividades potencialmente contaminantes a la Administración autonómica se efectuará "tras una evaluación preliminar, cuyo contenido será fijado por el Consejo de Ministros, previa consulta a las Comunidades Autónomas", el recurrente considera que con ello se va más allá de las competencias estatales en materia de medio ambiente (art. 129.1.23 CE), mientras que el Tribunal Constitucional es de la opinión de que se trata de una impugnación puramente preventiva, atendiendo al hecho de que se desconoce lo que decidirá el Consejo de Ministros — esto se repite, esencialmente, en la posterior STC 180/2013, de 23 de octubre de 2013 - Por una parte, esto es así, pero, por otra, se parte de una extensión más bien indefinida de una potestad estatal, en principio, legislativa, que, en el fondo, permite una ocupación densa de la materia por parte de la Administración central del Estado. Aunque seguramente criticable, no es sorprendente atendiendo a los precedentes. 


\subsection{Otro caso de multiplicidad competencial: la Ley de Economía Sostenible}

La Sentencia 174/2013, de 10 de octubre de 2013 (BOE, núm. 267, de 7 de noviembre de 2013), se pronuncia en relación con diversos aspectos de la Ley $2 / 2011$, de 4 de marzo, de Economía Sostenible, a raíz de la impugnación realizada por la Generalitat de Cataluña de algunos de sus preceptos, poniendo de manifiesto el solapamiento entre las políticas públicas sectoriales — con sus respectivos títulos competenciales- y las estrategias ambientales de carácter global que la Ley controvertida alinea en torno a la idea de sostenibilidad. La impugnación se refiere, en concreto, a los artículos 101 y 102 —referidos a la movilidad sostenible_, a los artículos 110 y 111 —relativos a la rehabilitación y mejora de las construcciones y los edificios- y, finalmente, a la disposición final primera de la Ley 2/2011.

En resumen, la representación procesal de la Generalitat entiende que el artículo 101 de la Ley conculca la competencia catalana en materia de transporte intracomunitario (art. 169.1 EAC), ya que considera que la competencia estatal recogida en el artículo 149.1.23 CE no permite al Estado llegar "al extremo de imponer un sistema de planificación de los transportes intracomunitarios mediante los planes de movilidad sostenible". En cuanto al artículo 102, el recurrente considera que se han traspasado los límites de las competencias estatales en relación con la atribución de subvenciones en la medida en que se vincula con lo previsto en el artículo anterior. Por otro lado, en cuanto a los artículos 110 y 111, la Generalitat entiende que se trata de preceptos "materialmente urbanísticos" que, por este motivo, se sitúan en el ámbito competencial de la comunidad autónoma, quedando vedados a la intervención estatal, que no podría ampararse en la competencia horizontal recogida en el artículo 149.1.13 CE. La disposición final primera se recurre parcialmente per relationem en la medida en que menciona los títulos competenciales que amparan los preceptos recurridos y que, a juicio del recurrente, no serían de aplicación, por lo que no cabe su invocación en el precepto mencionado.

En el curso de la tramitación del proceso constitucional se ha aprobado la Ley 8/2013, de 26 de junio, de rehabilitación, regeneración y renovación urbanas, que, en particular, deroga los citados artículos 110 y 111 de la Ley de Economía Sostenible. Del nuevo 
régimen jurídico previsto en la mencionada Ley 8/2013 el Tribunal Constitucional deduce la desaparición de la controversia competencial en la medida en que, respecto al primero, "no habilita ya para aprobar la correspondiente modificación de forma independiente por los procedimientos de aprobación de las normas reglamentarias, ni atribuye a la modificación realizada de tal forma los mismos efectos que los planes de ordenación urbanística", mientras que, respecto al segundo, en relación con "la ocupación de las superficies de espacios libres o de dominio público, no se establece una autorización ex lege, sino que tal ocupación ha quedado convertida en una posibilidad que ha de ser concretada por los instrumentos de ordenación urbanística, sin que la norma introduzca, por tanto, una regla urbanística de directa aplicación” (FJ 2. ${ }^{\circ}$. Por otro lado, en relación con la disposición final primera, el Tribunal Constitucional considera que, no habiéndose aludido a ella en la tramitación del "cauce de resolución de conflictos previsto en el art. 33.2 de la Ley Orgánica del Tribunal Constitucional (LOTC)", el recurso de inconstitucionalidad presentado tendría "un objeto más amplio que el inicialmente determinado como controvertido en el mencionado acuerdo de la subcomisión de seguimiento normativo, prevención y solución de conflictos de la Comisión Bilateral Generalitat-Estado". El exceso en la formulación del recurso sería inadmisible en la medida en que el proceso aludido supone una delimitación del objeto del proceso de constitucionalidad, por lo que el Tribunal Constitucional considera que "no forman parte del objeto del recurso los apartados 1, párrafos primero y último, y 2 b) de la disposición final primera y ello sin perjuicio de que, dado que han sido impugnados por conexión, esta impugnación no sea autónoma, sino que se relaciona directamente con las de los preceptos sustantivos de la Ley de economía sostenible que han sido recurridos" (FJ 2. ${ }^{\circ}$ ).

En cuanto al artículo 102 de la Ley de Economía Sostenible, "fue modificado por la disposición final trigésimo primera de la Ley 2/2012, de 29 de junio, de presupuestos generales del Estado para el año 2012”. Sin embargo, el Tribunal Constitucional considera que ello "en nada afecta a lo aquí discutido, consistente en el denunciado exceso competencial en relación con las subvenciones al transporte urbano y metropolitano en el que incurriría el precepto impugnado así como a su carácter arbitrario y contrario al art. 9.3 CE, sin que tampoco la impugnación pueda ser calificada como preventiva, pues lo que el órgano autonómico discute es, precisamente, el hecho de que las futuras ayudas o subvenciones estatales en esta materia puedan 
quedar condicionadas en la forma que el precepto establece y no el momento en que dicho condicionamiento se produzca" (FJ 2. ${ }^{\circ}$ ).

En conclusión, el objeto del recurso se contrae, finalmente, a los artículos 101 y 102 de la Ley de Economía Sostenible. En cuanto a ello, el Tribunal Constitucional reconoce que "atendiendo a su contenido la regulación relativa a los planes de movilidad sostenible se encuadra, conforme a su objeto prioritario, en la materia transportes, de competencia exclusiva autonómica en los casos en que el mismo no supere dicho ámbito territorial", aunque también deban tenerse en cuenta "las consideraciones esencialmente medioambientales que han llevado al legislador estatal al intento de aplicar el punto de vista de la sostenibilidad" (FJ 3.'). En consecuencia, el Tribunal Constitucional plantea que se produce un solapamiento de títulos competenciales sobre un mismo ámbito material que cabrá resolver, aunque, a priori, ambos títulos tengan méritos objetivos para ser de aplicación. Por ello, el juez de constitucionalidad considera que "la cuestión que ha de responderse es si el Estado puede legítimamente condicionar la competencia exclusiva autonómica en uso de sus competencias básicas, como pueden ser las relativas al medio ambiente, que, en este caso, recaen sobre un mismo objeto jurídico, los planes de movilidad sostenible" (FJ 3. ${ }^{\circ}$ ).

El Tribunal Constitucional considera que la "solución pasa por determinar si la regulación cuestionada puede merecer o no la consideración de legislación básica dictada por el Estado al amparo de la competencia prevista en el art. 149.1.23 CE, pues sólo si se le reconoce tal condición resultaría constitucionalmente admisible la regulación cuestionada" (FJ 4. ${ }^{\circ}$ ), en la medida en que los preceptos estarán amparados por el título competencial estatal si gozan de la condición de básicos en la materia concernida, ya que, en ese caso, se considera legítimo que condicionen el ejercicio de competencias autonómicas sectoriales.

A partir de aquí, el Tribunal Constitucional considera lo siguiente:

a) En relación con el primer apartado, cree que se limita "a formular desde una perspectiva principial o general los objetivos que han de perseguir los mencionados planes de movilidad sostenible. Por ello, en tanto que formula una serie de principios generales orientativos (reducción del transporte individual en beneficio de sistemas colectivos y de modalidades no motorizadas de transportes, por ejemplo) a efectos de que se definan posteriormente las actuaciones que permitan alcanzar el objetivo 
tendente a la implantación de formas de desplazamiento más sostenibles, se adecua con naturalidad a la competencia estatal ejercida en la materia de medio ambiente" (FJ 5. ${ }^{\circ}$ ), lo que, en su opinión, es constitucional.

b) En relación con el segundo, "la queja formulada ha de ser desestimada pues el precepto se limita a señalar, con un mero carácter enunciativo y sin más concreciones, los posibles ámbitos territoriales de los mencionados planes de movilidad, de lo que no puede deducirse obligación alguna respecto a su necesaria existencia en todos los casos" $\left(\mathrm{FJ} 5 .^{\circ}\right)$.

c) En relación con el tercer apartado, el Tribunal considera que la cuestión controvertida se centra en la remisión a la Estrategia Española de Movilidad Sostenible. Planteado en estos términos, según el Tribunal,

[...] la remisión que efectúa la de la Ley de economía sostenible a la estrategia española de movilidad sostenible no puede, por ese solo hecho ser considerada inconstitucional sino, todo lo más, una deficiencia de técnica legislativa, en la que en principio este Tribunal no debe entrar, salvo que se apreciase una extralimitación de las bases estatales desde un punto de vista material. Desde esta segunda perspectiva, sin embargo, no cabe apreciar que la remisión a la estrategia española de movilidad sostenible vulnere las competencias de la Comunidad Autónoma, por relación a lo que se entiende como un contenido extenso y preciso de dicha estrategia española de movilidad sostenible tal como alega la Generalitat de Cataluña en su demanda, pues ya hemos comprobado que, en atención a su naturaleza, se trata de un documento lo suficientemente genérico, en cuanto que establece puras orientaciones en materia de movilidad, para permitir desarrollos diversos, sin que, por lo demás, la demanda concrete los extremos en que se manifestaría ese carácter concreto y detallado que denuncia.

d) En cuanto al cuarto apartado, el TC considera que "se limita a fijar un contenido mínimo de los planes de movilidad sostenible y en cuya regulación no cabe apreciar vulneración competencial alguna. Por un lado, no impide que los citados planes puedan tener otros contenidos. Tampoco, por otro, hace indicación alguna en cuanto al modo en que los reclamados por la norma (diagnóstico de la situación, objetivos a lograr, medidas a adoptar, mecanismos de financiación y procedimientos para su seguimiento, evaluación y revisión y análisis de los costes y beneficios económicos, sociales y ambientales) hayan de llevarse a cabo". 
En cuanto al artículo 102, el Tribunal Constitucional considera que "el Estado, más allá de la soberanía que ostenta sobre sus propios fondos, se halla competencialmente habilitado para condicionar el otorgamiento de ayudas con cargo a sus propios recursos a un objetivo, como el que, vinculado a la consecución de un transporte público más sostenible", sin que quepa alegar violación del artículo 9.3 CE. De algún modo, el Tribunal Constitucional es de la opinión de que es legítimo que el Estado fije orientaciones materiales en su política de subvenciones, lo que no impide que pueda plantearse la inconstitucionalidad de "cada concreta línea de ayudas en los que ese condicionamiento se produzca", pero, en cualquier caso, el reproche de inconstitucionalidad no puede proyectarse sobre el criterio general. En conclusión, el Tribunal Constitucional considera legítimos los dos preceptos finalmente enjuiciados, con una argumentación que parece atendible, particularmente en relación con el primero de ellos, que, por su carácter genérico y transversal, parece ajustarse razonablemente a la fijación de unos mínimos en relación con la protección del medio ambiente que se proyectan sobre una determinada política sectorial, condicionando su desarrollo justamente por su condición de básicos.

\section{Subvenciones en relación con asociaciones y fundaciones relacionadas con la protección del medio ambiente}

El siguiente objeto de análisis lo constituye la Sentencia 113/2013, de 9 de mayo de 2013 (BOE, núm. 133, de 4 de junio de 2013), que se refiere, una vez más, a la controvertida cuestión del uso del spending power por parte de las instituciones centrales del Estado en relación con cuestiones que se solapan a las competencias materiales de las comunidades autónomas, en este caso, en relación con la protección del medio ambiente. Así, en este caso, la Generalitat de Cataluña formalizó ante el Tribunal Constitucional un conflicto positivo de competencia contra los artículos 1, 2, 3, 5, 7, 8 y 13 y la disposición final primera de la Orden ARM/1593/2009, de 5 de junio, por la que se establecen las bases reguladoras para la concesión de subvenciones, a asociaciones declaradas de utilidad pública y fundaciones adscritas al protectorado del Ministerio de Medio Ambiente, y Medio Rural y Marino, para fines de interés social de carácter medioambiental. 
La representación procesal de la Generalitat argumenta que el objeto de las subvenciones reguladas por la Orden coincide con la definición del título competencial autonómico contenido en el artículo 144 del Estatuto de Autonomía de Cataluña (EAC), y, sin embargo, "la regulación establecida por dicha orden ministerial no contiene ninguna participación de las Comunidades Autónomas, ni de la Generalitat de Cataluña, en la regulación ni en la gestión de dichas ayudas, pretendiendo su amparo competencial en el título de legislación básica en materia de medio ambiente previsto en el art. 149.1.23 CE, de acuerdo con la disposición final primera de la propia orden”.

Recuerda, asimismo, la Generalitat que "el art. 114 del Estatuto de Autonomía de Cataluña referido a actividad de fomento, establece [...] en su apartado tercero que, en las materias de competencia compartida, corresponde a la Generalitat precisar normativamente los objetivos a los cuales se destinen las subvenciones estatales y comunitarias europeas territorializables, y también completar la regulación de las condiciones de otorgamiento y toda la gestión, incluyendo la tramitación y la concesión de las mismas. El apartado 5 del mencionado art. 114 prevé que la Generalitat participe en la determinación del carácter no territorializable de las subvenciones estatales y comunitarias europeas, y que, asimismo, participe, en los términos que fije el Estado, en la gestión y la tramitación de dichas subvenciones".

Por su parte, el Abogado del Estado, considerando la posibilidad de que, excepcionalmente y de modo justificado, se centralice la gestión de subvenciones, cree que en este caso el hecho de que, en el preámbulo de la Orden ARM/1593/2009, se señala expresamente que "se procede a la gestión centralizada de las presentes ayudas por razones de supraterritorialidad, al tratarse de entidades sin ánimo de lucro que no están regionalizadas y al ser las actividades de carácter medioambiental que se contemplan como subvencionables de ámbito supraautonómico".

A la hora de resolver, el Tribunal Constitucional parte de lo dicho en la STC 13/1992, de 6 de febrero, que, en particular, afirmó que "no existe una competencia subvencional diferenciada resultante de la potestad financiera del Estado". Esto es, el spending power no altera el orden competencial, sino que debe reconducirse a este. Por otro lado, el Alto Tribunal considera que el "ámbito material en el que debe incardinarse la resolución cuestionada es, por tanto, el relativo a medio ambiente, por ser ésta la materia más directamente afectada, tal y como queda, asimismo, confirmado por la remisión que se 
realiza al art. 149.1.23 CE en la disposición final primera de la Orden ARM/1593/2009, de 5 de junio" $\left(\mathrm{FJ} \mathrm{4}^{\circ}{ }^{\circ}\right)$.

Seguidamente, el TC señala que "la centralización en el Estado de funciones relacionadas con la regulación del régimen de otorgamiento y de la gestión de las ayudas sólo puede tener lugar en supuestos excepcionales que aparezcan plenamente justificados" (FJ 6. ${ }^{\circ}$. En definitiva, se trata, por lo tanto, de si se da la justificación que autoriza al Estado para la centralización. Apelando a lo dicho en la STC 38/2012, de 27 de marzo - comentada en la crónica correspondiente al número 3-2 de la revista-, el Tribunal recuerda que la supraterritorialidad de los concurrentes a las ayudas "no es, por sí misma, una razón suficiente para proceder a la centralización total de la regulación del régimen de otorgamiento y de la gestión de las ayudas. El criterio territorial del radio de acción de los solicitantes no puede resultar relevante, pues el ejercicio de las competencias de desarrollo de las ayudas y de gestión de las mismas por parte de la Comunidad Autónoma cabría siempre en la medida en que el programa se ejecute en su propio territorio. Por tanto, el hecho de que las entidades beneficiarias de las ayudas vengan desarrollando su actividad, o lo tengan previsto en su título constitutivo, en distintas Comunidades Autónomas no puede determinar, por sí solo, la centralización de la regulación y la gestión de aquéllas".

Continuando con lo dicho en aquella sentencia, el Tribunal recuerda que, atendiendo al carácter excepcional de la facultad estatal en este caso, "como tuvimos ocasión de afirmar en la ya citada STC 38/2012", "correspondería al Estado la carga de probar que en los supuestos de aquellas ejecuciones con alcance supraautonómico la ejecución no puede llevarse a cabo mediante mecanismos de cooperación o coordinación, bien sean de naturaleza vertical —entre el Estado y las Comunidades Autónomas-, bien de naturaleza horizontal —entre Comunidades Autónomas-, ya que tales son los instrumentos que han de servir, en principio, para resolver la eventual contraposición de intereses entre los distintos entes territoriales" (STC 38/2012, de 26 de marzo, FJ 8. ${ }^{\circ}$ ). Considera que ello no se ha producido en este caso, con lo que se conculcan las competencias de la Generalitat en los siguientes artículos de la Orden controvertida: el inciso "que por su naturaleza no sean susceptibles de territorialización" del artículo 1 y los artículos 3, 5, 7, 8 y 13 .

Por ello, dado que la Orden controvertida no ha agotado sus efectos, resulta "obligado entonces declarar que al Gobierno de la Generalitat de Cataluña corresponderá la 
titularidad y el ejercicio de las competencias reconocidas en los preceptos que, siendo susceptibles de ser aplicados los sucesivos ejercicios, hemos calificado contrarios al orden constitucional de distribución de competencias" (FJ 9. ${ }^{\circ}$, aunque dicha declaración no afecta a las resoluciones que hayan concedido o denegado las ayudas cuestionadas ya dictadas y notificadas.

La aplicación de la doctrina más o menos consolidada del Tribunal Constitucional respecto al spending power del Estado en relación con las competencias compartidas con las comunidades autónomas no merece mayor comentario. Una vez más, el Tribunal Constitucional ataja la vis expansiva del Estado a la hora de utilizar su capacidad de gasto saltando por encima de los límites que le imponen las competencias autonómicas. En este caso, además, como la norma impugnada tiene vocación de continuidad, los efectos del pronunciamiento se extienden pro futuro, lo que no ha sucedido cuando el Alto Tribunal ha tenido que pronunciarse en relación con una resolución que se agotaba en su propia aplicación. Finalmente, debe notarse que lo dicho en la Sentencia comentada se reitera en la 163/2013, de 26 de septiembre (BOE, núm. 254, de 23 de octubre de 2013), que tiene el mismo objeto procesal, en este caso, en relación con un conflicto de competencias presentado por el Gobierno de Aragón. Por ello, no merece mayor comentario que lo ya expresado en relación con la 113/2013.

\section{Caza y protección del medio ambiente: la proyección de la legislación básica como protección mínima sobre la normativa autonómica en el ámbito de la caza}

En la Sentencia 114/2013, de 9 de mayo (BOE, núm. 133, de 4 de junio de 2013), se resuelve el recurso de inconstitucionalidad presentado por el presidente del Gobierno contra el último párrafo del artículo 10 de la Ley 13/2004, de 27 de diciembre, de Caza de la Comunidad Valenciana, en la redacción dada a este por el artículo 2 de la Ley 7/2009, de 22 de octubre, de reforma de los artículos 7 y 10 de la Ley 13/2004. La controversia se centra en el hecho de que la mencionada modificación legislativa introduce el parany entre los métodos de caza tradicionales en la Comunidad Valenciana y, en consecuencia, entre los métodos de caza legalmente admitidos en territorio valenciano, lo que, a juicio del abogado del Estado, supone la introducción de un método de caza no selectivo, "expresamente prohibido tanto por la Directiva 
79/409/CEE, de 2 de abril de 1979, relativa a la conservación de aves silvestres, como por la Ley 42/2007, de 13 de diciembre, de patrimonio natural y de la biodiversidad".

Esta última contradicción conllevaría la nulidad de la legislación valenciana en la medida en que constituiría una vulneración de la legislación básica del Estado en materia de protección del medio ambiente, ya que conllevaría un grado de protección inferior al establecido como mínimo por la legislación estatal. En definitiva, la ordenación mediante mínimos que supone la competencia estatal en relación con la legislación básica en materia de protección del medio ambiente delimitaría las posibilidades de la legislación sectorial autonómica — en este caso, la caza — en aquello que tuviera trascendencia ambiental.

Por su parte, la representación procesal de las Cortes Valencianas defiende la admisibilidad del parany, ya que, remitiéndose a la exposición de motivos de la Ley impugnada, "es un método cinegético tradicional en la Comunidad Valenciana, practicado a lo largo de los últimos siglos, consistente en la captura de túrdidos (tordos o zorzales) mediante empleo de liga (sustancias adhesivas), dispuesta sobre varetas que se colocan en árboles expresamente podados y preparados al efecto, atrayéndolas previamente mediante reclamo bucal o especímenes enjaulados de las mismas especies. Este método está hondamente arraigado en la cultura y paisajes rurales de muchas comarcas valencianas, y su práctica se ha realizado durante siglos en el marco de un equilibrio con la conservación del medio agrario, ayudando a la prevención de daños que causan tales aves a determinados tipos de cultivo". Las Cortes Valencianas defienden, a partir de la evidencia científica disponible, que se encuentra en las excepciones que puedan reconocerse en la legislación de los Estados en relación con la Directiva, en caso de que "no hubiera otra solución satisfactoria, por un conjunto de motivos entre los que se encuentra el de permitir, en condiciones estrictamente controladas y de un modo selectivo, la captura, retención o cualquier otra explotación prudente de determinadas aves en pequeñas cantidades".

En consecuencia, el Gobierno valenciano considera, por una parte, que no existe incompatibilidad con la Directiva y, por otra, que la legislación estatal alegada no tiene carácter de básica, por lo que la norma impugnada sería expresión de una actividad legítima por parte del legislador valenciano, de acuerdo con las competencias de caza recogidas en el Estatuto, sin que haya vulneración del derecho comunitario, que prevé la excepción de la legislación básica estatal por cuanto la norma incompatible con la 
disposición valenciana que aduce el presidente del Gobierno no tendría carácter de básica. La representación procesal del Gobierno valenciano amplía el argumento subrayando que el cumplimiento del derecho comunitario no justifica nuevas atribuciones competenciales para las instituciones centrales del Estado, por lo que, en todo caso, la transposición de la Directiva relativa a la caza corresponde a las instituciones valencianas, que, por otro lado, la han hecho, a su juicio, correctamente. Por lo tanto, el debate se centra, en definitiva, en el carácter básico de la disposición estatal, esto es, si establece un mínimo de protección en relación con el medio ambiente que vincula a la Comunidad Autónoma o, en cambio, no puede considerarse básico y, en consecuencia, las instituciones valencianas pueden hacer su propio juicio en relación con el régimen de excepciones que prevé la normativa comunitaria.

El Tribunal Constitucional se remite en su pronunciamiento a lo ya dispuesto en la STC 69/2013, de 14 de marzo de 2013, donde, en relación con la disposición estatal que justificaría la inconstitucionalidad del precepto impugnado, optaba por un punto de vista conservacionista, como ya advertía en la crónica precedente, donde comenté la Sentencia citada. El Tribunal se aparta otra vez, abriendo una nueva línea jurisprudencial, de lo que decía en la STC 102/1995, de 26 de junio, lo que no es reprochable, sino que es una manifestación del carácter evolutivo de la jurisprudencia constitucional, que, en este ámbito, parece adaptarse a una modificación de la sensibilidad social en relación con la práctica de la caza.

Por lo demás, en un saludable ejercicio de diálogo interjurisdiccional, el Tribunal Constitucional tiene en cuenta lo dicho por el Tribunal de Justicia de las Comunidades Europeas (STJCE, de 9 de diciembre de 2004, asunto C-79/03, Comisión de las Comunidades Europeas contra España) en relación con la práctica del parany, considerado como un método no selectivo de caza en el sentido de la Directiva. Esto sirve para mostrar la conexión entre la protección del medio ambiente y la determinación de los métodos de caza admisibles, así como para defender, efectivamente, el carácter básico de la disposición estatal —que establece un mínimo razonable y coherente con el derecho comunitario- y, en consecuencia, la inconstitucionalidad del precepto autonómico. Por otro lado, cabe decir que con la Sentencia comentada continúa el rosario de resoluciones del Tribunal Constitucional suscitadas por la Ley 42/2007, de 13 de diciembre, del Patrimonio Natural y de la Biodiversidad, que también genera una de las sentencias que analizaré a continuación. 


\section{La protección de la biodiversidad: materia controvertida}

La protección de la biodiversidad es, efectivamente, una materia competencialmente controvertida que ha ido generando numerosos pronunciamientos del Tribunal Constitucional desde la tantas veces citada STC 102/1995, de 26 de junio. Me referiré a continuación a dos nuevos pronunciamientos del Tribunal Constitucional en esta materia, los realizados a través de las sentencias 138/2013, de 6 de junio de 2013 (BOE, núm. 157, de 2 de julio de 2013), y 146/2013, de 11 de julio de 2013 (BOE, núm. 183, de 1 de agosto de 2013).

\subsection{Nuevamente, la Ley 42/2007 a discusión}

La Ley 42/2007 ha dado lugar a una renovada litigiosidad en este ámbito, cuya última manifestación es la citada STC 138/2013, de 6 de junio - antes, cabe citar la mencionada STC 69/2013, de 14 de marzo, y la 87/2013, de 11 de abril, comentadas en la crónica correspondiente al número anterior- En el caso que nos ocupa, se enjuician una serie de preceptos de la Ley mencionada a raíz del recurso de inconstitucionalidad promovido por el Consejo de Gobierno de la Comunidad de Madrid.

Concretamente, se impugnan los artículos 4 (fomento de acuerdos voluntarios con los propietarios y usuarios para la planificación y gestión de espacios naturales protegidos y especies amenazadas), 9 (elaboración y actualización de un inventario español del patrimonio natural y de la biodiversidad a cargo del Ministerio de Medio Ambiente), 10 (sistema de indicadores de dicho inventario), 11 (informe anual para la descripción del estado y la evolución del patrimonio natural y de la biodiversidad), 16.2 (directrices ministeriales de ordenación de los recursos naturales, que condicionan los planes de ordenación de los recursos naturales que aprueben las comunidades autónomas), 20 (corredores ecológicos), 23.b.1 (plan de ordenación de los recursos naturales para zonas bien conservadas amenazadas por un factor de perturbación), 24, 25 y 26 (catálogo español de hábitats en peligro de desaparición como instrumento de carácter administrativo y ámbito estatal dependiente del Ministerio de Medio Ambiente), 45.1 (obligaciones de las comunidades autónomas en relación con la adopción de medidas de protección de las zonas especiales de conservación y de las zonas de especial protección para las aves), 62.3.j (prohibición de la tenencia y el uso de munición que contenga plomo, durante el ejercicio de la caza y el tiro deportivo en determinadas zonas 
húmedas), 66.2 (Comité MaB español como órgano colegiado de carácter asesor y científico adscrito al Ministerio de Medio Ambiente) y, finalmente, 72 (custodia del terreno, entre entidades y propietarios de fincas, con el fin de conservar el patrimonio natural y la biodiversidad).

Se trata, pues, de un recurso complejo y comprensivo en el que se suscitan múltiples cuestiones de controversia. Sin entrar en las argumentaciones de las partes, paso a comentar el pronunciamiento del Tribunal, que parte del hecho de que "[t]odas las impugnaciones se fundamentan en motivos competenciales que, como proponen las partes, deben examinarse a la luz del art. 149.1.23 CE [...] y del art. 27.7 del Estatuto de Autonomía de la Comunidad de Madrid, que asigna a esta Comunidad el desarrollo tanto legislativo como reglamentario" de la legislación básica en materia de medio ambiente, así como las correspondientes funciones ejecutivas y la posibilidad de "establecer normas adicionales de protección" (FJ 1. $\left.{ }^{\circ}\right)$. Por otro lado, deben consignarse las modificaciones que han experimentado los artículos 72.2 -mediante la Ley 25/2009, de 22 de diciembre, de modificación de diversas leyes para su adaptación a la Ley sobre el libre acceso a las actividades de servicios y su ejercicio, la conocida como Ley Ómnibus - y 45.1 -mediante la Ley 11/2012, de 19 de diciembre, de medidas urgentes en materia de medio ambiente-.

Pues bien, en cuanto a los artículos 4 y 72, el Tribunal Constitucional considera que "[1]a circunstancia de que estas previsiones puedan llegar a condicionar las políticas medioambientales autonómicas no implica por sí vulneración competencial alguna, pues en eso consiste, justamente, que corresponda al Estado la legislación básica medioambiental (art. 149.1.23 CE), que es una ordenación común para todo el territorio nacional, sin perjuicio del necesario margen de desarrollo autonómico (STC 101/2005, de 20 de abril, FJ 5)". Parece que, efectivamente, dichas disposiciones no trascienden el ámbito competencial estatal, pues, o bien determinan un marco jurídico sobre el que proyectar la custodia —incardinable dentro del concepto de legislación básica一, o bien se refieren a su implementación en espacios de titularidad estatal.

En cuanto a los artículos 9, 10 y 11, el Tribunal salva su constitucionalidad apelando a la jurisprudencia establecida en la seminal STC 102/1995. Sin embargo, el planteamiento de aquella resolución de que "el deber estatal de dejar un margen de desarrollo de la legislación básica por la normativa autonómica es menor que en otros ámbitos”, que, en el fondo, remite a la previa STC 149/1991, de 4 de julio, debe 
discutirse ya que no hay ningún fundamento constitucional para sostenerlo y la idea de desarrollo legislativo no parece que deba modificarse en este caso - lo que sí sucede con el propio concepto de legislación básica, modulable de acuerdo con la singularidad de las normas adicionales de protección en materia de medio ambiente- Cabe considerar aquí, pues, un exceso en la competencia estatal, que debería haberse equilibrado con el correspondiente apoderamiento de las comunidades autónomas en un tipo de medida, la planificación, en que confluyen caracteres de legislación básica y de ejecución.

Por lo demás, el Tribunal Constitucional se remite, asimismo, a la ya citada STC 69/2013. Todo ello parece apuntar hacia un apoderamiento quizá excesivo de las instituciones centrales del Estado en una materia en que la coordinación entre administraciones y la combinación de estrategias generales con el know how local no solo parece razonable, sino directamente extraíble del marco constitucional — cabría citar aquí el principio de cooperación, desarrollado en el ámbito del derecho ambiental en los países germánicos $\mathrm{y}$, seguramente, piedra de toque de una política ambiental equilibrada entre los intereses locales y los generales-. En este sentido, la opinión del TC en este aspecto particular del recurso debe juzgarse con cierta reserva, aunque, ciertamente, la dicción literal de las normas muestra, asimismo, una prudencia y espíritu de colaboración del legislador estatal que justifican suficientemente su constitucionalidad. En conclusión, el tenor literal de la norma permite salvar sin grandes reservas su constitucionalidad, aunque el Tribunal Constitucional quizá debiera haber matizado la extensión de la competencia estatal, así como la necesidad de la cooperación en una materia como esta.

Justamente, en el enjuiciamiento del artículo 16.2 el Tribunal Constitucional alude a la necesidad de "coordinación", aunque, en puridad, debería haberse referido a la "cooperación" en esta materia. Salva de nuevo la norma, de acuerdo con lo ya dicho en las SSTC 102/1995 y la más reciente 69/2013, ya comentada, como he dicho, en la crónica anterior. En relación con el artículo 20, el TC considera que "resulta justificada la competencia estatal para establecer en concepto de legislación básica condicionamientos a la planificación ambiental de las Comunidades Autónomas" (FJ 6. $\left.{ }^{\circ}\right)$. Nuevamente, la posición del juez de la constitucionalidad parece razonable en aras de una respuesta coherente a los retos que representa la protección de la biodiversidad, 
atendiendo a la competencia constitucionalmente reconocida al Estado en esta materia (art. 149.1.23 CE).

También en relación con la impugnación del artículo 23 de la Ley, el TC se remite a lo ya dicho en la 102/1995, sin que quepa mayor comentario. Esta es también la matriz hermenéutica utilizada para resolver el recurso en relación con los artículos 24, 25 y 26. Nuevamente, el TC hace referencia a su jurisprudencia anterior $y$, en particular, a la citada STC 102/1995. Aquí, la argumentación es similar a la precitada en relación con los artículos 9, 10 y 11, y, en consecuencia, debe someterse a la misma crítica. Cabe reconocer, es cierto, la dificultad de deslindar la legislación básica, el desarrollo legislativo y la ejecución en determinados aspectos de la protección de la biodiversidad, ya que el bien jurídico (básicamente) protegido y los instrumentos ejecutivos para su protección pueden entremezclarse, pero, en todo caso, debe reivindicarse, de acuerdo con el marco constitucional, una aproximación concertada a la problemática que relativiza el apoderamiento del Estado, al mismo tiempo que tiene en consideración la posible expansión de la legislación básica por la propia necesidad de tutela del bien jurídico. En cualquier caso, debe reconocerse que resolver en estos casos no es fácil y que el Tribunal Constitucional hace gala de cierta prudencia al abordar las cuestiones controvertidas.

En cuanto al artículo 45, el Alto Tribunal se remite a la decisión ya expresada en la STC $69 / 2013$, sin que quepa mayor comentario que el ya formulado en la crónica anterior. Lo mismo sucede con el artículo 62.3.j. Finalmente, en relación con el 66.2, el TC se remite al pronunciamiento interpretativo formulado en la ya tantas veces citada Sentencia, con lo que repito la remisión a la crónica anterior. En definitiva, el Tribunal Constitucional navega en este caso en las procelosas aguas de la gestión de la biodiversidad, que reclaman una respuesta concertada desde diferentes instancias institucionales, de acuerdo con un marco constitucional que permite construirla, pero que plantea supuestos conflictivos en su aplicación práctica. Si en otras cuestiones relativas a la protección del medio ambiente la jurisprudencia del Tribunal Constitucional es abiertamente discutible, en este ámbito cabe subrayar sus esfuerzos por construir una posición razonable y sensible con la problemática planteada. 


\subsection{Determinación de las especies protegidas}

Finalmente, debo referirme al conflicto positivo de competencia promovido por el Gobierno de Canarias contra el Real Decreto 139/2011, de 4 de febrero, para el desarrollo del Listado de Especies Silvestres en Régimen de Protección Especial y del Catálogo Español de Especies Amenazadas, que ha sido resuelto por la STC 146/2013, de 11 de julio. Se discute aquí el desarrollo reglamentario de las previsiones contenidas en la precitada Ley 42/2007, en la medida en que "la determinación de lo básico [... que] se contiene en el Real Decreto 139/2011, al incluir en el listado y catálogo, con los efectos que de tal inclusión se hacen derivar de la Ley del patrimonio natural y de la biodiversidad, determinadas especies que, por ser endémicas, sólo existen en el territorio canario, o que, sin serlo, encuentran en Canarias su único punto de distribución en todo el territorio nacional".

En este sentido, la representación procesal del Gobierno canario considera que "[n]o cabe, en este sentido, legislación especial para una sola Comunidad Autónoma que pretenda ampararse en la competencia sobre legislación básica, porque carecería del fundamento y del alcance de ésta según la jurisprudencia del Tribunal Constitucional. Las particularidades propias de la flora y fauna del archipiélago canario, que por su lejanía y por su insularidad, goza de una biodiversidad única, no pueden formar parte de un 'común denominador normativo' que cabe predicar de una norma dictada con carácter básico" (el subrayado es mío).

Pues bien, el Tribunal considera que el hecho de que determinadas especies se encuentren solamente en el ámbito de una comunidad autónoma concreta - lo que es más que plausible si la comunidad autónoma es insular, como es el caso- no impide que las instituciones centrales del Estado intervengan en su protección, en ejercicio de la competencia en materia de legislación básica en relación con la protección del medio ambiente, ya que "la singularidad de determinadas especies identificadas únicamente en el archipiélago canario en el momento de su inclusión en el listado o el catálogo no es motivo para excluir el ejercicio de la competencia estatal ex art. 149.1.23 CE, teniendo además en cuenta que dicha singularidad es susceptible de variación por causas naturales o por las propias medidas adoptadas para su protección" (FJ 4. ${ }^{\circ}$ ).

En mi opinión, aunque la intervención del Estado puede estar justificada en este caso en la medida en que determinadas manifestaciones de la biodiversidad merecen una tutela 
que puede integrarse en el concepto de legislación básica, ya que su interés en relación con la protección del medio ambiente trasciende el marco territorial en el que se inscriben, la argumentación del Tribunal Constitucional es manifiestamente inadecuada. Esta se basa en una cuestión de hecho sin relevancia —en realidad, incluso contraproducente desde el punto de vista de la protección de la biodiversidad - como es la posible extensión de las especies concernidas más allá del marco donde se ubican en un momento histórico determinado, en vez de considerar estrictamente su valor desde el punto de vista de la biodiversidad, independientemente del ámbito territorial donde se desarrollan. Esto es lo que justificaría aquí la intervención de las instituciones centrales del Estado, en la medida en que cierta especie local puede ser de interés general por su importancia para la preservación de la biodiversidad, que es un bien jurídico integrado en la protección del medio ambiente que propugna el artículo $45 \mathrm{CE}$, lo que sostendría la intervención del legislador básico en este ámbito — de un modo excepcional, es cierto-, ya que marcaría un mínimo común denominador en relación con la composición de la biosfera que trascendería las competencias autonómicas de desarrollo, aunque tal mínimo fuera territorialmente circunscribible a una cierta comunidad autónoma. 